\title{
Addressing Cultural Challenges in a Global Service Learning Project to Reduce Plastic Waste in Rural India
}

\author{
Jeffrey R. Seay, PhD, PE \\ Associate Professor \\ Chemical and Materials Engineering \\ University of Kentucky \\ jeffrey.seay@uky.edu \\ John C. Higgins \\ Undergraduate Research Assistant \\ Mechanical Engineering \\ University of Kentucky \\ john.higgins@uky.edu
}

\author{
Elango Jeyaraj \\ Director \\ Organization of Development Action and Maintenance \\ odamelango@gmail.com
}

\author{
Chandni A. Joshi \\ Undergraduate Research Assistant \\ Chemical and Materials Engineering \\ University of Kentucky \\ chandniben.joshi@uky.edu
}

\author{
Sarah F. Willett \\ Undergraduate Research Assistant \\ Chemical and Materials Engineering \\ University of Kentucky \\ sarah.willett@uky.edu
}

\begin{abstract}
In the summer of 2015, a group of chemical and mechanical engineering undergraduate students from the University of Kentucky Paducah Extended Campus Program participated in a Global Service Learning and Sustainability course focused on implementing a project to convert waste plastic into a sustainable liquid fuel in rural southern India. The successful construction, operation and testing of the liquid fuel in local diesel powered irrigation pumps will be described. Service learning projects conducted in other countries often face cultural hurdles that are quite different than in traditional study abroad programs. Working side-by-side with local people requires adapting to cultural practices that may be quite different from the students' expectations. To address this, cultural aspects and social sustainability were included in a lecture component of the service learning course as well as in the implementation of the service project. The learning outcomes for this course included providing students with clear understanding of the key issues of sustainability and sustainable community development in rural and underdeveloped regions and educating them as to how engineers must consider cultural factors when working in underdeveloped regions. This service learning project was conducted in collaboration with the Organization of Development Action and Maintenance (ODAM) in Tiruchuli, India.
\end{abstract}

Index Terms: Appropriate technology, sustainability, fuel oil, education abroad

\section{INTRODUCTION}

Engineers generally tend to be technically oriented and results focused. Meeting technical challenges is what motivates many engineers. However, it is important for engineers to realize 
that they are part of a global community and that the processes and products they design can have far reaching impacts ${ }^{1}$. This is especially true in developing countries where even technically wellconceived projects may not fit the needs of the communities for which they are intended. Additionally, cultural differences complicate the work environment. Students engaged in global service learning projects need to understand the role engineers play in society. Solving technical challenges is only one aspect of the engineer's job. Increasingly, engineers must consider the broader impacts of their design choices. The case study presented herein will document the organization of a Global Service Learning course that introduces the students to the concepts of social responsibility and cultural awareness. This course included both a traditional classroom lecture component and a hands on service learning project focused on applying the principles of green chemistry, appropriate technology and sustainable engineering to address the problems of waste plastic accumulation in underdeveloped regions. This course was offered as a six-week summer term course in the Indian state of Tamil Nadu. The Global Service Learning and Sustainability course was developed in collaboration with the Organization of Development Action and Maintenance (ODAM), an NGO headquartered in Tiruchuli, India. The case study presented here documents the successful implementation of this technology in Tamil Nadu, India and the cultural hurdles that must be addressed in an international service learning project.

\section{ObJectives ANd Organization OF The Global SERVice Learning CourSe}

The service learning project described herein is incorporated into a study abroad course on Global Service Learning and Sustainability. The topics covered in this multidisciplinary engineering course include: the engineer in society; sustainability; service learning; and appropriate technology. Specific emphasis is placed on rural and underdeveloped regions. Three textbooks were utilized for the course: Engineering and Sustainable Community Development by Juan Lucena, Jen Schneider, and Jon A. Leydens ${ }^{2}$; Engineers, Society and Sustainability by Sarah Bell ${ }^{3}$; and Engineers within a Local and Global Society by Caroline Baille $^{4}$. The three credit hour course is designed to give students an awareness of the role of the engineer in modern society, with a particular emphasis on global issues in developing regions particularly sub-Saharan Africa and India. Upon completing this course, students are expected to have a clear understanding of the key issues of sustainability and sustainable community development in rural and underdeveloped regions.

Within this context, the Global Service Learning and Sustainability course has three broad objectives. The first is to introduce the concept of sustainability to undergraduate students. Sustainable products and processes must be economically profitable, environmentally benign and socially acceptable. This was a guiding principle for the course - ensuring that students take environmental and social factors into consideration when making design choices. These factors - particularly social impacts - do not always come naturally to engineers. Considering the tradeoffs necessary to satisfy the three principles of sustainability was an important objective of the course.

The second objective is to provide students with a broader perspective on how engineering can benefit society, but can sometimes also result in negative unintended consequences. It is critical for students to consider the possible negative effects of technological innovation. For manufactured goods in particular, the impacts on society along the entire life cycle must be considered. The problem of waste plastic, for example, is a negative consequence of the 
widespread availability of prepackaged goods. Engineering students must learn to take these kinds of effects into consideration for any engineering project.

The final objective is to introduce students to different cultures. The course was designed to foster community engagement and understanding the needs of the local community and the local culture. Development occurs at different speeds and with different objectives depending on region and local culture. It is important for engineers to recognize and respect these differences. In addition to the academic and project based activities, the local host ensured that the students had the opportunity to experience local culture. This was achieved via interaction with local students and by visiting regional sites of cultural importance.

The Global Service Learning and Sustainability course was organized into two components, a classroom portion and a hands-on service project. While in India, the students met for two 50minute classroom sections per week. The first week of the course was focused on an introduction to the principles and concepts of sustainability and engineering in a global context. These class meetings were organized as traditional lectures utilizing PowerPoint slides to supplement the lecture material. The remaining classroom meetings were organized as in-class discussions based on previously assigned reading material. For each assignment, students were required to submit 1-page summaries of the reading at the beginning of each class. The class time consisted of guided discussion of the reading material and how it did or did not apply to the group's experience in India. The reading assignments are given in Table 1.

TABLE 1

GLOBAL SERVICE LEARNING AND SUSTAINABILITY READING ASSIGNMENTS

\begin{tabular}{|c|l|}
\hline Number & \multicolumn{1}{c|}{ Reading Assignment } \\
\hline 1 & $\begin{array}{l}\text { The Origins of Sustainability } \\
\text { ESS - Chapter 1 }\end{array}$ \\
\hline 2 & $\begin{array}{l}\text { Society and Technology } \\
\text { ESS Chapter 3 / ESCD - Chapter 1 }\end{array}$ \\
\hline 3 & $\begin{array}{l}\text { Introduction to Appropriate Technology } \\
\text { ESCD - Chapter 2 }\end{array}$ \\
\hline 4 & $\begin{array}{l}\text { Industry vs. Community } \\
\text { ESCD - Chapter 3 }\end{array}$ \\
\hline 5 & $\begin{array}{l}\text { Engineering and Community Engagement } \\
\text { ESCD - Chapter 4 }\end{array}$ \\
\hline 6 & $\begin{array}{l}\text { Listening to Community } \\
\text { ESCD - Chapter 5 }\end{array}$ \\
\hline 7 & $\begin{array}{l}\text { Case Studies in Engineering for Development } \\
\text { ESCD - Chapter 6 and 7 }\end{array}$ \\
\hline 8 & $\begin{array}{l}\text { A History of Engineering and Society } \\
\text { ELGS - Chapter 3 }\end{array}$ \\
\hline 9 & $\begin{array}{l}\text { Development and Globalization } \\
\text { ELGS - Chapter 4 }\end{array}$ \\
\hline
\end{tabular}

Note: ESS = Engineers, Society and Sustainability; ESCD = Engineering and Sustainable Community Development , ELGS = Engineers within a Local and Global Society.

The second component to the course was the implementation of the service learning project. Each day, the students traveled to the ODAM facility and spent 5 to 6 hours working with the ODAM staff on their service learning project. The details of the project will be discussed in a 
section to follow, but the project basically involved assembling an apparatus to convert waste plastic into fuel oil, conducting experimental runs with local materials and training the ODAM staff to operate the apparatus.

\section{PARTNERSHIP WITH ODAM}

In order for a course that includes an in-country service learning component to be successful, a local partner is essential ${ }^{1,5}$. To this end, a partnership was established with ODAM in Tiruchuli, India (see Figure 1). Established in 1995, ODAM works to address rural poverty, women's empowerment, child welfare, climate change, and human rights to education, health, and safety. The organization's work is spread across 278 villages, impacting over 14,000 men, women, and children in the southern part of the state of Tamil Nadu in India.

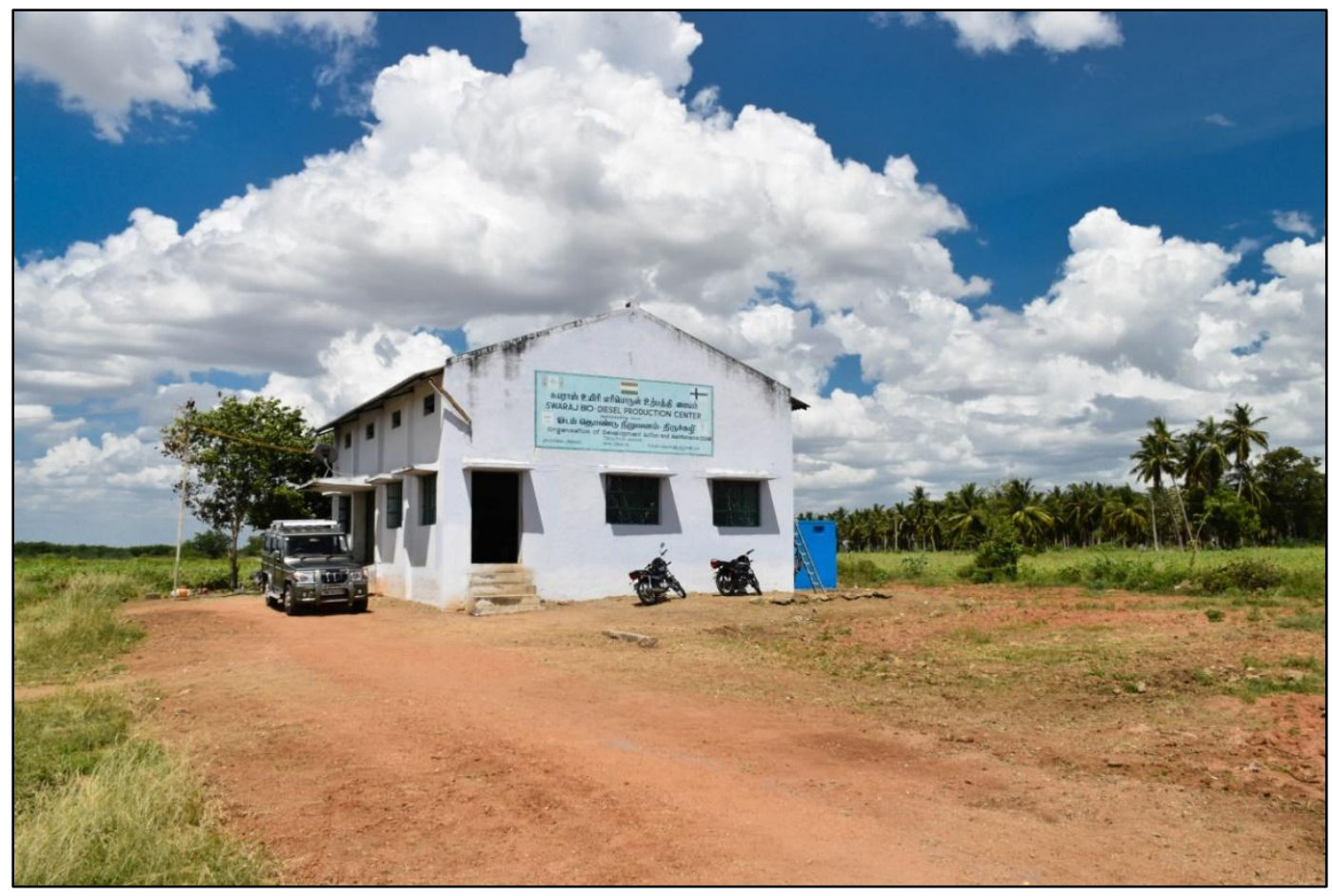

FIGURE 1

ODAM FACILITY IN TIRUCHULI, INDIA

In 2005 ODAM's focus changed towards climate victims who are affected by the negative impacts of climate change, particularly marginal farmers, charcoal producers and tribal communities. ODAM's projects are intended to strengthen the livelihoods of the climate victims through energy efficient techniques and products that enhance the income level of the same communities. From a global perspective, the ultimate aim is to reduce carbon emissions in order to mitigate the impact of climate change.

Preparing for a formal study abroad program outside of a university setting is particularly challenging. Over the years, ODAM has received hundreds of volunteers from Europe, US and 
Australia who worked in different projects like teaching English in a special school for drop-out girls and renewable energy projects. Accordingly, the ODAM staff is able to understand the expectations of the people from outside India. Since ODAM does not maintain dormitory or cafeteria facility, arrangements for room and board for the 12 students and 1 faculty member had to be made. Organizing food for the students was the major challenge faced by the ODAM staff. Only after the 4th week were the expectations of the students fully realized by the ODAM staff. Housing was arranged for the six-week duration of the program in a western style hotel in the nearby city of Aruppukottai. Two vehicles and drivers were retained to transport the group to and from the ODAM facility every day. Meals were prepared at the ODAM facility for the group by local cooks hired specifically for the study abroad program. This allowed ODAM to ensure proper hygiene to avoid any food-borne illness and to accommodate any particular dietary restrictions.

The original plan was to hold lectures at the ODAM facility, but due to the heat, classes were instead held in the hotel where the group was staying. The total in country budget for the program was 2,160 USD per student. Each student was eligible to apply for a study abroad travel grant of up to 1,500 USD, which helped to offset the out of pocket costs for the students. Air travel to India was paid separately by the students. Fundraising and private donations helped offset this cost as well.

As previously mentioned, the Global Service Learning and Sustainability course included 4 cultural visits that were organized by ODAM. The students visited Rameshwaram, which is an island in the Bay of Bengal, the Meenakshi Temple in the city of Madurai, Courtallam, which is a culturally significant waterfall, and Thekkady, in the neighboring state of Kerala, to learn about sustainable living and eco-tourism (see Figure 2).

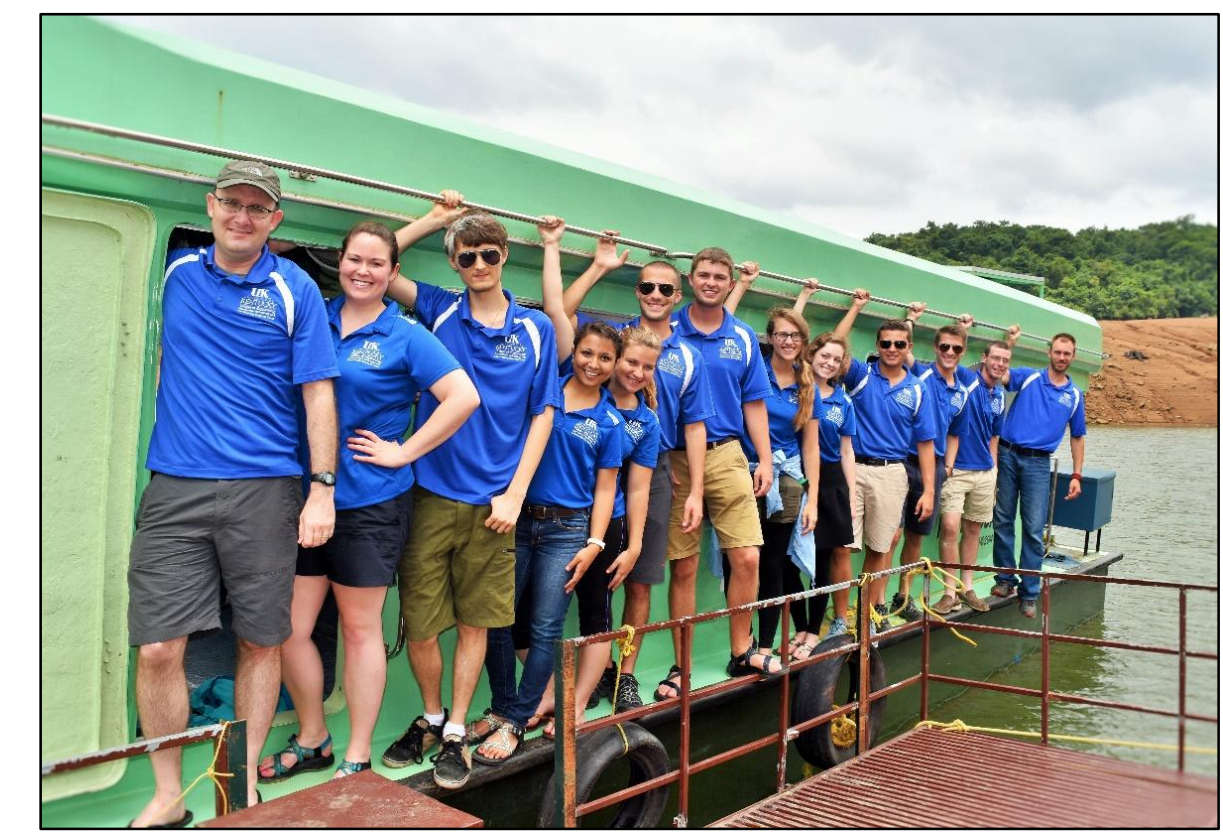

FIGURE 2

PROFESSOR SEAY WITH THE STUDENT GROUP NEAR THEKKADY, KERALA 


\section{Service Learning Project Background}

Population growth and urbanization in developing countries has led to an increase in waste generation. As communities develop, the availability of prepackaged goods increases. These goods are often packaged in plastic. Of course there are many benefits to the availability of such goods but a critical problem is dealing with the waste packaging. In many rural or underdeveloped communities, organized trash collection is not available. As a result, trash often accumulates which can lead to problems ranging from public health concerns to waterway pollution to the general aesthetics of a community (see Figure 3). In fact, 2014 estimates put the mass of plastic currently polluting the world's oceans at over 250,000 tons, or over 5 trillion pieces of plastic ${ }^{6}$. Addressing these concerns was the primary focus of this service learning project.

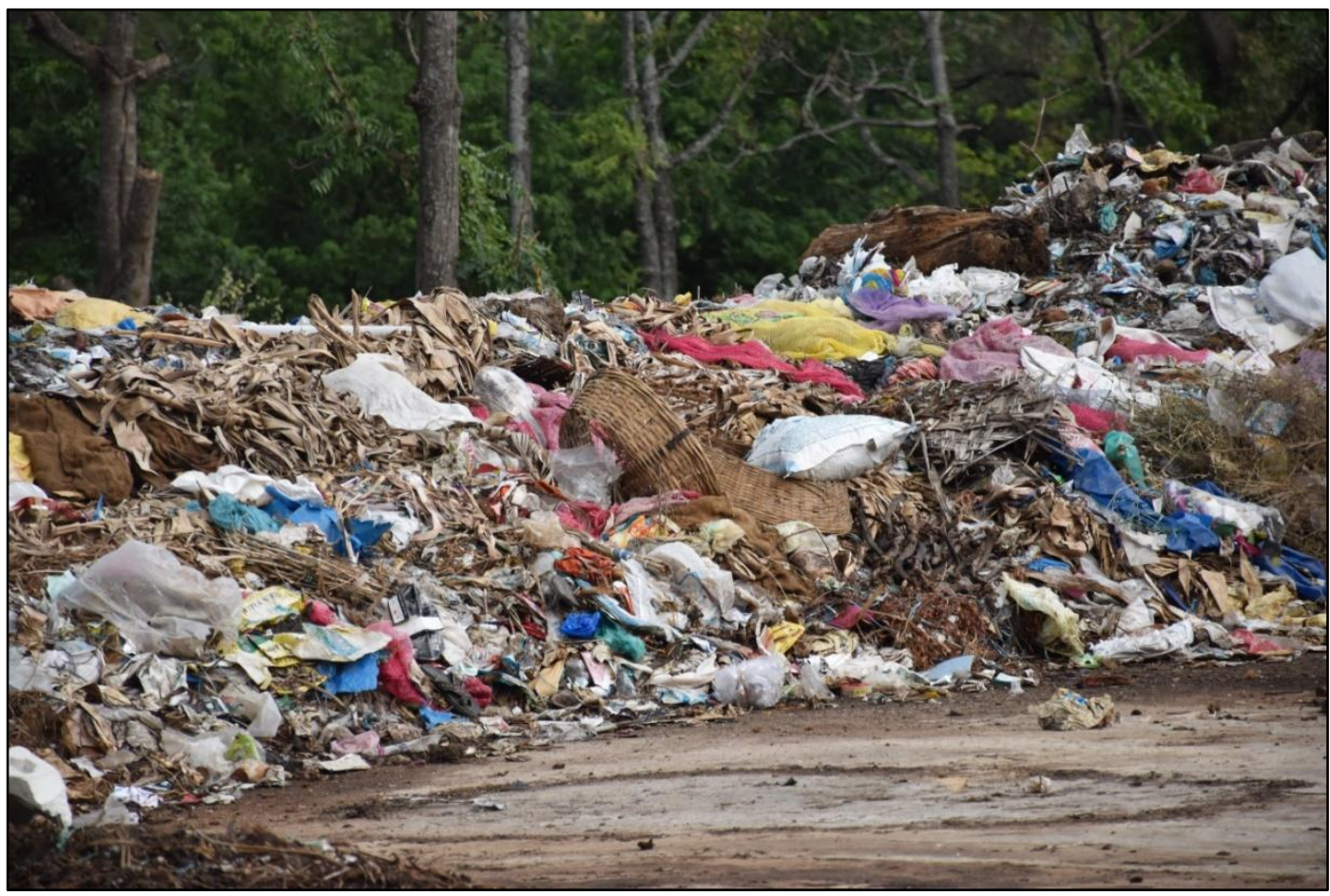

FIGURE 3

TRASH DUMP SITE IN TAMIL NADU, INDIA

\section{Service Based Design Project}

As previously described, plastic waste is a problem around the world. It threatens the environment and public health. Although recycling is an option in developed areas, the infrastructure is often lacking in rural or underdeveloped regions. The focus of this service learning project is to implement a low-cost, sustainable, appropriate technology based processor that allows local people in developing regions to utilize plastic waste to produce a product that benefits the local community. The successful outcome of this project will provide a market for 
waste plastic as well as entrepreneurial opportunities for developing communities to meet a fundamental global need. Although this service learning project has been implemented in Tamil $\mathrm{Nadu}$, the outcomes have applications globally.

The chemistry for this project is based on thermal decomposition. The process is appropriate for high/low density polyethylene (HDPE/LDPE), polypropylene (PP) and polystyrene (PS) ${ }^{7}$. These plastics are typical components of urban trash. HDPE and LDPE are identified by the numbers 2 and 4 respectively stamped in the recycling symbol. These materials used in plastic grocery bags, bottle tops, milk jugs and food containers. LDPE is typically more flexible than HDPE. PP is indicated by the number 5 stamped on the recycling symbol and is used in many plastic items such as buckets and plastic lawn chairs, for food packaging, and other items like drinking straws. PS is indicated by recycling number 6. PS can be in the form of Styrofoam packaging, or in rigid form such as plastic cutlery. The key feature of these plastics is they are composed of only carbon and hydrogen. Oxygen containing plastics like polyethylene terephthalate and chlorine containing plastics like poly vinyl chloride are not suitable for this process. As the plastic is heated in the processor it melts and decomposes. As the polymers breakdown the resulting molecules get shorter, transitioning through wax, diesel fuel, kerosene, gasoline and finally synthesis gas. Although precise control in a reactor based on appropriate technology principles is not practical, the proposed reactor as designed produces a fuel oil suitable for diesel engines as well as kerosene cook stoves (see Figure 4). Although based on simple chemistry, this project sets a benchmark for innovation by demonstrating that green chemistry and appropriate technology can be merged to meet a global solid waste problem. Once established in Tamil Nadu, this process can spread to any area of the world where waste plastic accumulates.

Two current government programs in Tamil Nadu made it an ideal location for this service learning project. First, the government is implementing a plastic waste reduction program. Collection centers around the state receive and sort waste plastic. This makes waste plastic cheap and readily available. The project will assist local government in meeting their waste reduction targets. Second, the government is battling an invasive tree species, Prosopis Juliflora. The species, native to Mexico, was introduced decades ago to provide a drought tolerant source of firewood ${ }^{8}$. However, it has proven to be a nuisance and the government is working to eradicate $\mathrm{it}^{8}$. This makes the firewood used to heat the process cheap and readily available.

The processor used to convert waste plastic into fuel oil has been designed using the principles of appropriate technology. Appropriate technology, originally described by E.F. Schumacher ${ }^{9}$, is focused on ensuring that technology is developed by considering the needs of people and understanding that people in different communities have different needs. In general, appropriate technology is small-scale, decentralized, labor-intensive, energy-efficient, environmentally sound, and locally controlled ${ }^{10}$. Meeting all of these criteria can be difficult, so trade-offs, such as trading efficiency for simplicity often have to be made.

\section{Challenges OF Working IN A RURAL REgion IN INDiA}

For the production of fuel oil, the students utilized the previously designed UKATS processor ${ }^{5}$. The UKATS processor is based on rocket stove technology and is constructed from locally sourced recycled barrels and scrap metal. A propane cylinder is used as the thermal decomposition reactor. Using a fire maintained in the base of the processor, a propane cylinder 
loaded with plastic was heated so that the plastic melted and vaporized. The processor is designed to be assembled with simple plumbing attachments and fittings (see Figure 4). Prototype processors shipped from the United States were used by the student team until locally fabricated processors could be built.

While in India, the students encountered some problems with the local fabrication of the processors. Some factors occurred that prompted changes in the original design. A primary change was that the fabrication of the processor changed from a barrel design to a rolled steel design. The local craftsmen made this change to more easily create the UKATS processor. The geometry of the processor itself also changed because of the varying sizes of propane cylinders available in the region. Being adaptable to the materials and construction methods available in the region is a hallmark of appropriate technology.

The students encountered several problems caused by technical differences between the United States and rural south India. Most of these problems stemmed from the use of commercial plumbing fittings for the apparatus. The threaded pipe available in India has a slightly different fit than the pipe fittings in the United States. Because of this problem, many of the pipe fittings leaked under operating conditions. To address these issues, the students worked with a local pipefitter. The pipefitter used methods of sealing the pipes that are uncommon in the United States such as wrapping string around the threads before tightening the pieces to seal them. An additional nontechnical issue that the students encountered was the communication barrier. It was difficult to give instructions to the locals and for the locals to understand the instructions. Overcoming these technical and non-technical challenges was critical for the ultimate success of the project.

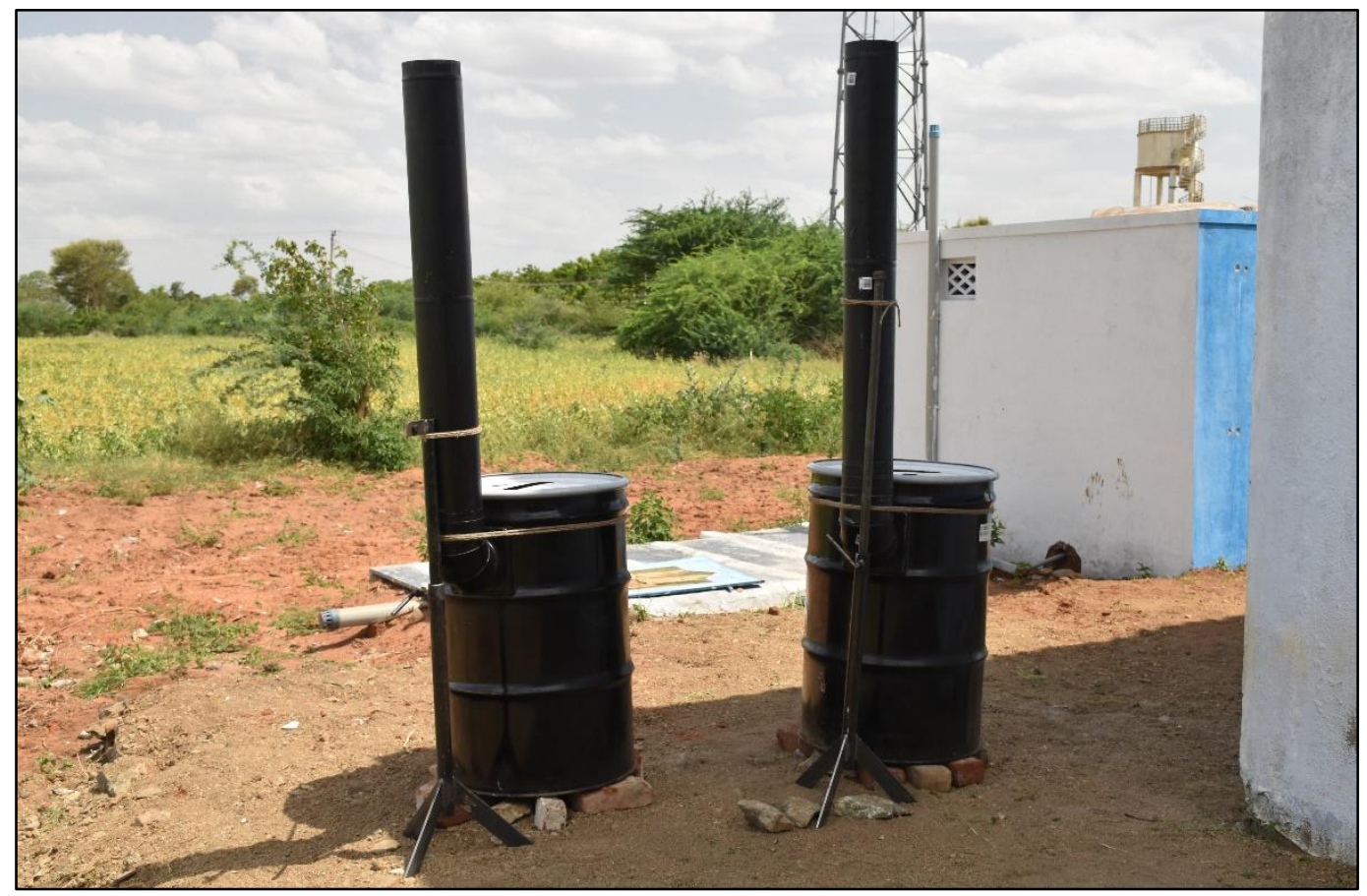

FIGURE 4

FUEL OIL PROCESSORS SET UP AT THE ODAM FACILITY 


\section{AdAPTing To South Indian Culture}

Rural India is culturally quite different from what students experience in the United States. One issue in particular is the role of women in society. The expectations of female students in the United States are that they will be treated as equals in the classroom and on campus. Women in rural India do not have these same expectations and do not have the same opportunities and respect as men. The impacts of these cultural differences were observed on the first working day in Tiruchuli.

Due to the climate in south India, all the students had planned to wear shorts for working at the ODAM facility. They were assured prior to departure that this would be acceptable. Although the shorts brought by the female students were certainly of an appropriate length by Western standards, women were told that they would not be allowed to wear shorts when working at ODAM and it was suggested that shorts not be worn anywhere outside of the hotel. This was not well received by the female students. In the United States it is generally acceptable for any culture to wear what their culture and beliefs permit. Therefore when the female students were told not to wear shorts it was offensive to them. However, since adapting to local culture is part of the study abroad experience, the female students were eventually accepting of this requirement.

The aspect that tended to bother the female students was not the cultural requirements regarding dress, but the fact that the rules applied differently to women and men. The male students were allowed to wear shorts if that was their preference. It was frustrating to the female students that the men had more rights in Tamil Nadu than they did. This was an aspect that was foreign to all of the students. Due to the hot dry climate, wearing long pants was particularly uncomfortable. Although the male students could have chosen to wear long pants in solidarity with their female colleagues, none did. Adapting to this cultural difference was a key learning experience for both the Americans and the Indian hosts. For future course offerings, all students will be required to wear long pants to avoid the feelings of inequality experienced by the female students.

\section{RESUlTS AND DisCUSSION}

From a technical perspective, the project was clearly a success. Locally gathered waste plastic was successfully converted into a fuel oil (see Figure 5). This fuel was then successfully tested in both cook stoves and in diesel powered irrigation pumps (see Figure 6). However, the goal of this project was to achieve the technical results while adhering to the three principles of sustainability: economically viable; environmentally benign; and socially acceptable. At the end of the project, all three of these principles had been achieved.

In the region, petrodiesel sells for 55 INR/liter. Separated waste plastic can be purchased for $20 \mathrm{INR} / \mathrm{kg}$ and the fire wood used to fuel the processor can be purchased for $4 \mathrm{INR} / \mathrm{kg}$ delivered. Based on a measured yield of $1 \mathrm{~L}$ of fuel oil per $1 \mathrm{~kg}$ of plastic, this process is economically viable, yielding a potential profit of up to 7 INR per liter. A scaled up design should yield an even higher profit.

The processor implemented by the student team is also environmentally benign. First, the production of a viable hydrocarbon fuel oil from waste plastic reduces solid waste accumulation in local trash dumps and along the streets in developing countries. This is beneficial because it 
minimizes the health concerns that accompany solid waste accumulation, such as waste entering watersheds, or becoming potential breeding grounds for disease carrying mosquitos. Second, the fuel oil produced from this process is more energy dense than the locally sourced petro diesel and kerosene. Experimental results indicate that the fuel oil is more calorific than petro diesel ${ }^{7}$, reducing overall $\mathrm{CO}_{2}$ emissions. Similarly, because the fuel is produced only from hydrocarbon plastics, there are no sulfur molecules present in the fuel oil, which means no $\mathrm{SO}_{\mathrm{x}}$ emissions when the fuel is burned ${ }^{7}$. Because clean plastic was used for the test runs in India, no residue was observed. However, if the feedstock were dirty or contained materials other than an appropriate plastic, a residue would have remained that would have had to be cleaned out of the processor and properly disposed of.

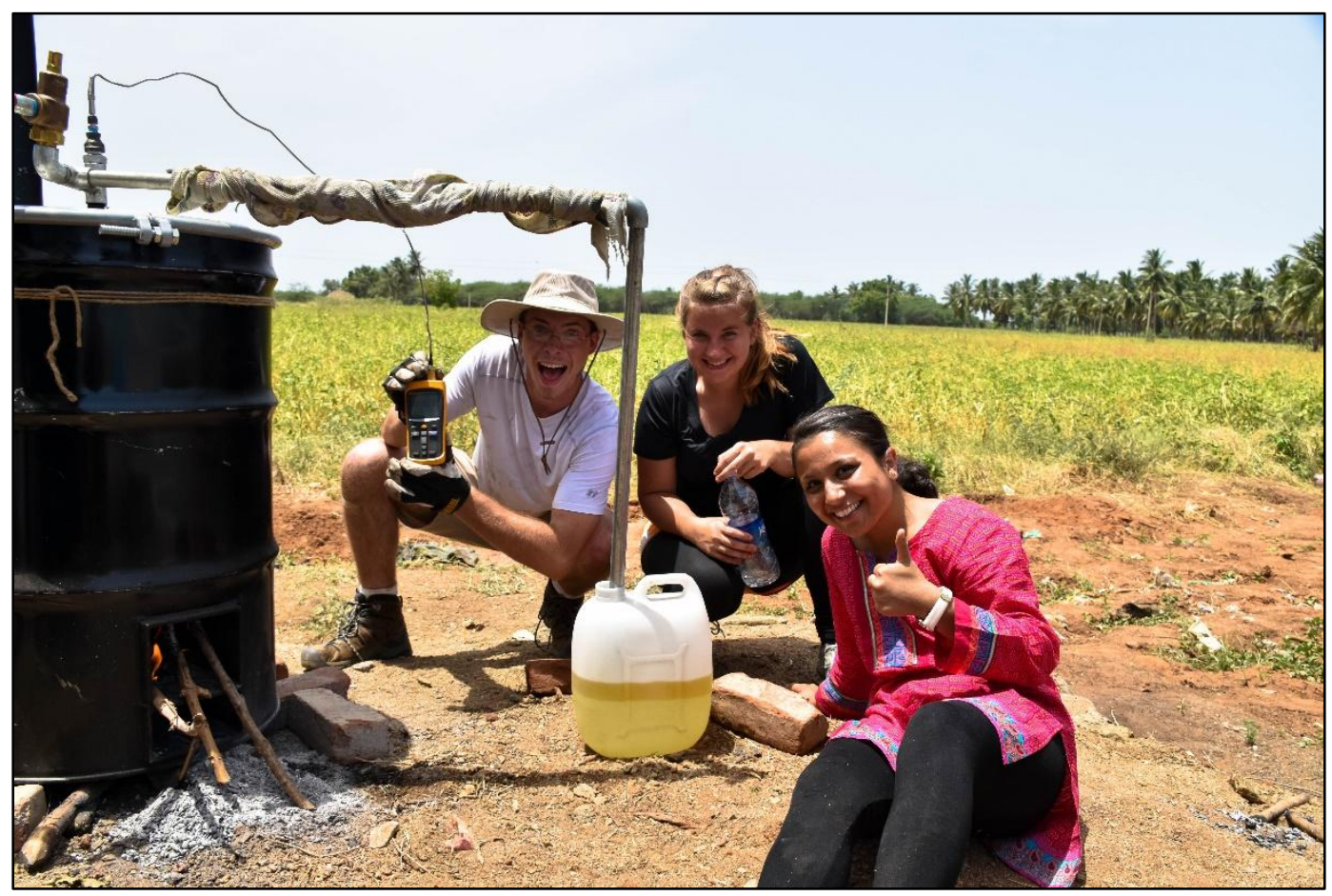

FIGURE 5

AUTHORS HIGGINS, JOSHI AND WILLETT IN INDIA WITH A SUCCESSFUL BATCH OF FUEL OIL

Perhaps the most difficult principle of sustainability to quantify is social acceptability. One way however that this can be achieved is by providing the community with the appropriate tools needed for development. The technology introduced by the students accomplishes this task by providing potential entrepreneurial opportunities for people in rural communities. In addition to the 7 INR/liter profit per batch of fuel oil, the technology is simple to operate, meaning that women can also utilize the processor to increase household standards of living. 
International Journal for Service Learning in Engineering, Humanitarian Engineering and Social Entrepreneurship Vol. 11, No. 1, pp. 19-31, Spring 2016

ISSN 1555-9033

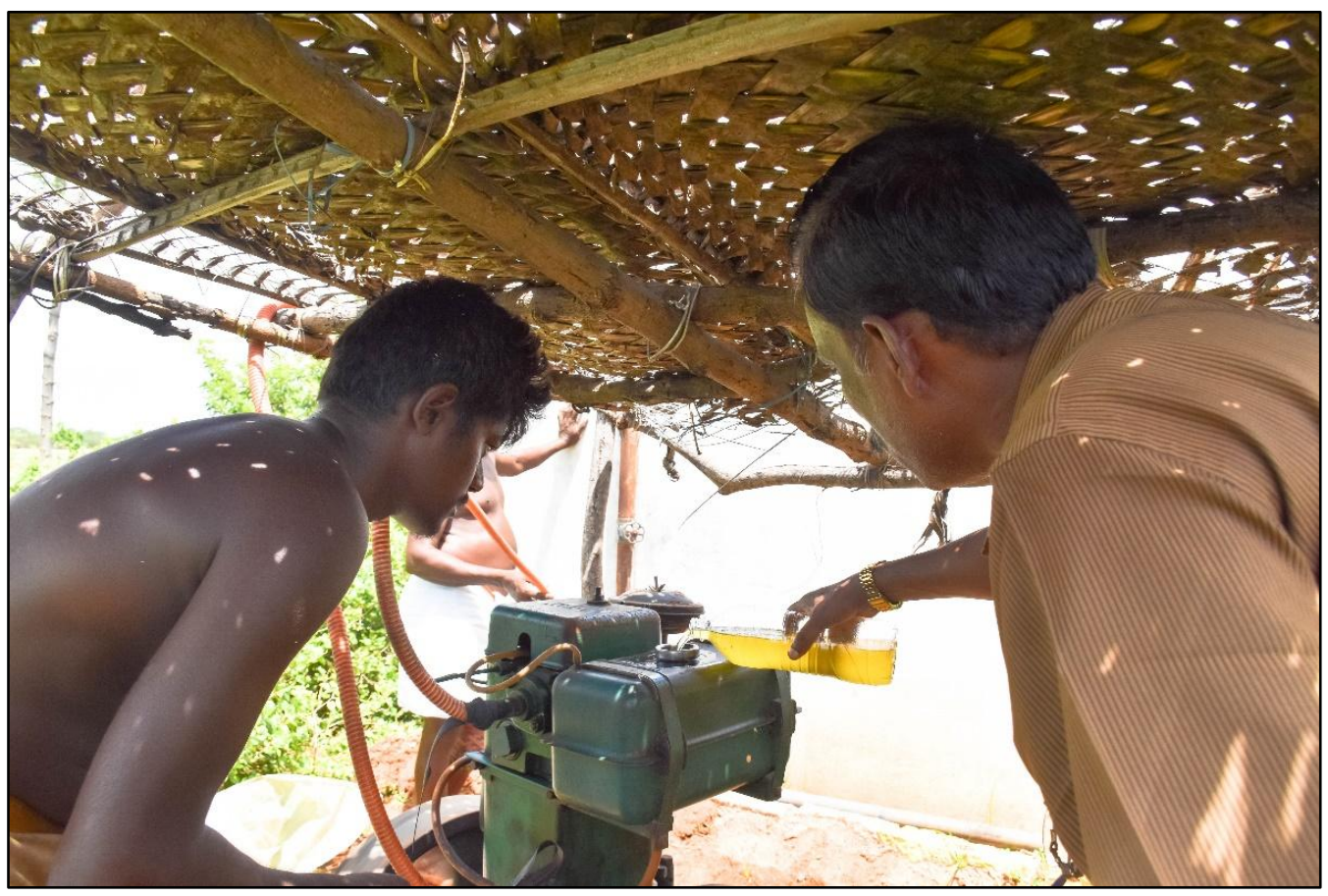

FIGURE 6

IRRIGATION PUMP TRIALS USING PLASTIC DERIVED FUEL OIL

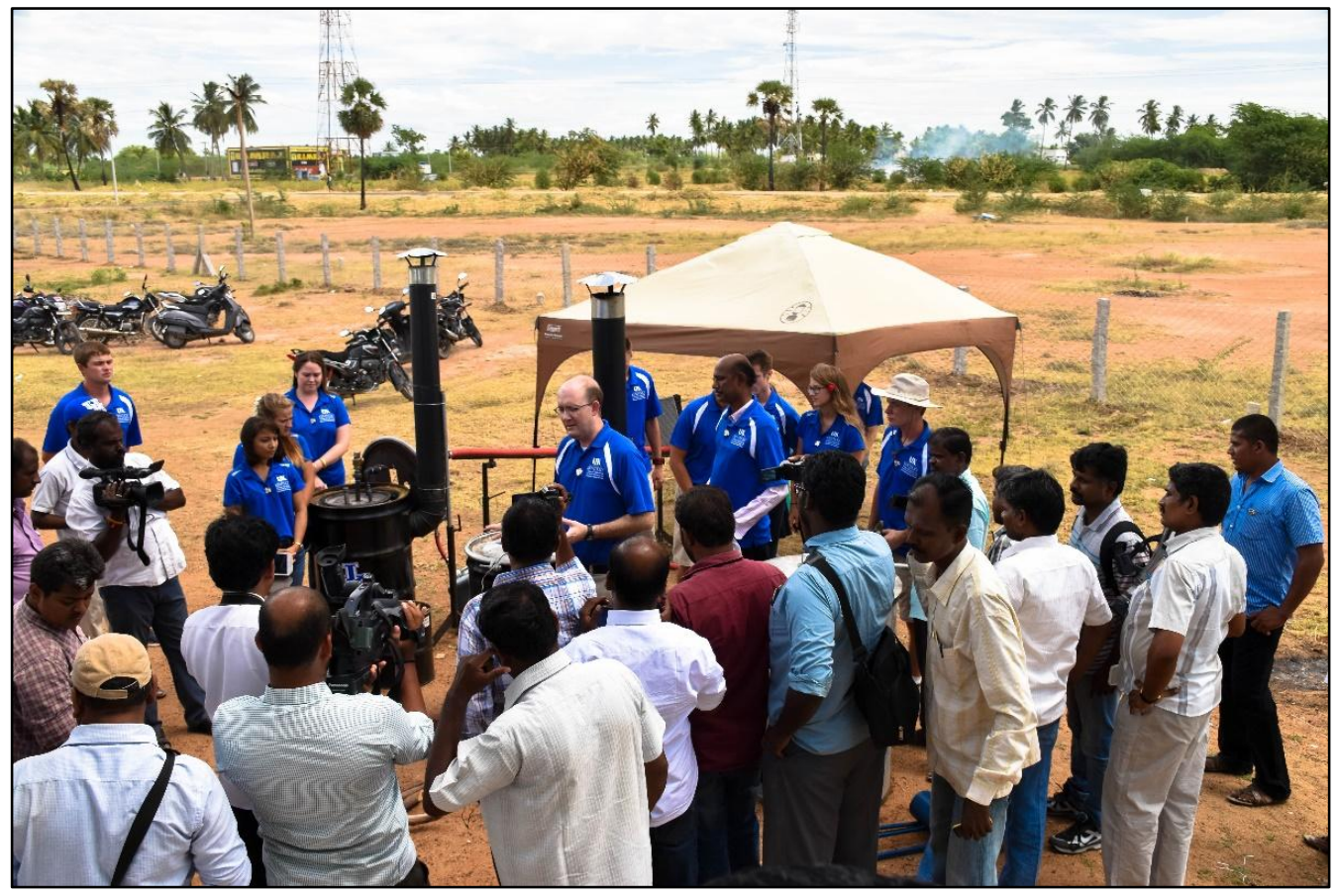

FIGURE 7

PRESS CONFERENCE AT ODAM FACILITY 
Finally, the hydrocarbon fuel oil provides a locally produced source of energy, making the processor a potentially transformative technology for the community. The fuel oil can be used for powering farm machinery, cook stoves, lamps and generators, providing the community with a reliable, local source of electricity. This increase in access to electricity leads to an increase in knowledge and education for the members of the community, further aiding them to emerge from poverty.

The service project results achieved by the University of Kentucky students were well received locally. At the conclusion of the stay in India, ODAM organized a press conference to publicize the results (see Figure 7). Details of the student project were reported on by two of the largest English language daily newspapers in India ${ }^{11,12}$, as well as numerous local Tamil language papers. This attention underscores the importance of this type of project to the region.

\section{CONCluSions AND PATH ForWARD}

The Global Service Learning and Sustainability course offered during the Summer of 2015 was successful in meeting both its academic and project objectives. However, the project cannot be considered a success until the technology introduced by the student team is adopted in villages around the country. The next offering of the course will include a project to bring prototype fuel oil processors to individual villages and train the local residents how to safely operate the process to produce fuel. To achieve this goal, the students will continue to work with ODAM to develop instructional pamphlets and videos that will be translated into Tamil and Hindi.

\section{ACKNOWLEDGEMENTS}

The authors wish to acknowledge the assistance of the Organization of Development Action and Maintenance in Tamil Nadu, India, the University of Kentucky Office for International Affairs and student participants, Elizabeth Behrens, Devan Buckhalter, Emily Burkhart, Maxwell Croft, William Croft, Keaton Johnson, Austin McCallon, Riley Pearcy, and Colton Tockstein, who contributed to this project.

\section{REFERENCES}

${ }^{1}$ Seay, J., I. Zama and B. Butler (2012): "International Partnership Helping to Bring Appropriate Biofuel Technology to Rural Cameroon”, International Journal of Service Learning in Engineering, Vol. 7, No. 2.

${ }^{2}$ Lucena, Juan, Jen Schneider, and Jon A. Leydens (2010): Engineering and Sustainable Community Development, Morgan and Claypool.

${ }^{3}$ Bell, Sarah (2011): Engineers, Society and Sustainability, Morgan and Claypool.

${ }^{4}$ Baille, Caroline (2006): Engineers within a Local and Global Society, Morgan and Claypool.

${ }^{5}$ Seay, J. and J. Lumkes (2014): "Multi-University Partnership for Global Service Learning in SubSaharan Africa", International Journal of Service Learning in Engineering, Special Issue, pp 367380, Fall 2014.

${ }^{6}$ Eriksen M, LCM Lebreton, HS Carson, M Thiel, CJ Moore, JC Borerro, F Galgani, PG Ryan, J Reisser (2014): "Plastic Pollution in the World's Oceans: More than 5 Trillion Plastic Pieces Weighing over 250,000 Tons Afloat at Sea", PLoS ONE, vol. 9 No. 12. 
International Journal for Service Learning in Engineering, Humanitarian Engineering and Social Entrepreneurship Vol. 11, No. 1, pp. 19-31, Spring 2016

ISSN 1555-9033

7 Joshi, C. and J. Seay (2015): "An Appropriate Technology Based Multifunctional Processor for Sustainable Production of Green Chemistry Based Products", AIChE Annual Meeting, November 2015.

${ }^{8}$ Imranullah, Mohamed (2014): "High Court Seeks Compliance Report." The Hindu. 10 February 2014.

${ }^{9}$ Schumacher, E.F. (1973): Small is Beautiful, Harper Collins.

${ }^{10}$ Hazeltine, B. and C. Bull (1999): Appropriate Technology: Tools, Choices, and Implications, New York: Academic Press.

${ }^{11}$ New Indian Express (2015): "US Team Lands in Turichuli for Study on Fuel from Waste Plastics", The New Indian Express (Madurai Edition), 22 July 2015.

${ }^{12}$ Hindu (2015): "Team Members Work on Production of Fuel Oil from Plastic Waste", The Hindu, 22 July 2015. 